Hepatocyte heterogeneity in the metabolism of fatty acids: discrepancies on zonation of acetyl-CoA carboxylase.

Quistorff, Bjørn; Katz, Nobert; A. Witters, Lee

Published in:

Enzyme

Publication date:

1992

Document version

Publisher's PDF, also known as Version of record

Citation for published version (APA):

Quistorff, B., Katz, N., \& A. Witters, L. (1992). Hepatocyte heterogeneity in the metabolism of fatty acids: discrepancies on zonation of acetyl-CoA carboxylase. Enzyme, 46((1-3)), 59-71. 


\title{
Hepatocyte Heterogeneity in the Metabolism of Fatty Acids: Discrepancies on Zonation of Acetyl-CoA Carboxylase
}

\author{
Bjorn Quistorff, Norbert Katz, Lee A. Witters \\ Department of Biochemistry, The Panum Institute, University of Copenhagen, Denmark; \\ Institute of Clinical Chemistry and Pathobiochemistry, University of Giessen, Germany, and \\ Department of Endocrine Metabolism, Dartmouth Medical School, Hanover, N.H., USA
}

Key Words. Metabolic zonation - Digitonin perfusion - Acetyl-CoA carboxylase . Fatty acid synthesis - Periportal - Perivenous - Rat liver

\begin{abstract}
Lipid metabolism appears to be less zonated than carbohydrate and protein metabolism. Studies on the zonation of lipid metabolism have been centered in particular on fatty acid synthesis which, according to the concept of metabolic zonation, should be a predominantly perivenous process while fatty acid oxidation should be periportal. There are, however, conflicting data on the activity gradients of lipogenic enzymes as well as measurements of actual synthesis of fatty acid and very low density lipoprotein. Data obtained by microdissection show a 1.5 - to 2 -fold higher activity of acetyl-CoA carboxylase and citrate lyase in the perivenous zone in agreement with measurements of the actual rate of fatty acid synthesis in preparations of hepatocyte, enriched in periportal or perivenous cells. On the other hand, results obtained with the dual-digitonin-pulse perfusion technique demonstrate the opposite gradient in the form of a 2- to 3-fold higher specific activity of acetyl-CoA carboxylase in the periportal zone based on measurements of the acetyl-CoA carboxylase protein proper. This specific activity gradient, which applies to male and not female rats, disappears almost completely in the fasted-refed animal, were lipogenesis is strongly induced. In this review we attempt to rationalize these discrepancies in the results as methodological differences which in particular apply to the following parameters: (1) expression of results (reference substance); (2) selectivity of zonal sampling, and (3) differences in methodology of acetyl-CoA carboxylase measurements. It is concluded that these factors could account for the discrepancies, but further studies, in particular on the zonation acetylCoA carboxylase mRNA, are required in order to further understand the zonation of lipid metabolism and its possible role in the metabolic regulation of the liver.
\end{abstract}


Table 1. Summary of data on zonation of ACC and fatty acid synthesis in rat liver

\begin{tabular}{llll}
$\begin{array}{l}\text { Method of } \\
\text { preparation }\end{array}$ & Sex PP & PV & $\begin{array}{l}\text { Ratio Refer- } \\
\text { pv/pp ences }\end{array}$ \\
\hline
\end{tabular}

Isolated PP and PV' cells

\begin{tabular}{lllllc} 
ACC & $\mathrm{M}$ & 0.49 & 0.73 & 1.5 & $9,10^{\mathrm{a}}$ \\
FA synthesis & $\mathrm{M}$ & 0.93 & 1.5 & 1.6 & $9^{\mathrm{b}}$ \\
& $\mathrm{F}$ & 39 & 34 & 1.0 & $15^{\mathrm{d}}$ \\
VLDL synthesis & $\mathrm{M}$ & 0.031 & 0.044 & 1.4 & $9^{\mathrm{c}}$ \\
\hline
\end{tabular}

Microdissection

$\begin{array}{llllll}\text { ACC } & \text { M } & 214 & 350 & 1.6 & 3^{\mathrm{c}} \\ & \mathrm{F} & 278 & 440 & 1.6 & 3^{\mathrm{e}}\end{array}$

$\begin{array}{lccccc}\text { Digitonin pulse perfusion } & & & \\ \text { ACC } & M & 9.3 & 3.1 & 0.33 & 12^{r} \\ & M & 3.4 & 1.3 & 0.38 & 12 g\end{array}$

i-c Data are expressed as nmol acetyl CoA, nmol of acetyl units and $\mathrm{nmol}$ of palmitate $/ \mathrm{min} / \mathrm{mg}$ of cellular protein.

d As ng ${ }^{3} \mathrm{H} / \mathrm{min} / \mathrm{mg}$ DNA.

e As nmol/min/g dry weight.

f As $\mathrm{nmol} / \mathrm{min} / \mathrm{mg}$ cytosolic protein.

g As $\mu \mathrm{moles} / \mathrm{min} / \mathrm{mg}$ ACC protein.

\section{Introduction}

Several important metabolic functions of the liver are zonated to different degrees ranging from absolute zonation, where cnzymes appear to be expressed only in one microcirculatory zone through proccsses showing 5- to 10 -fold periportal (PP) perivenous (PV) gradients, to enzymes of a zonation of 1.5- to 2-fold. Metabolic zonation is believed to play a role in the metabolic regulation of the liver and in the metabolic interaction between the liver and other organs. Various aspects of this phenomenon are described in this supplement and have indeed been reviewed recently $[1,2]$.
It is our primary intention in this article to discuss the zonation of fatty acid synthesis and, in particular, the zonation of the activity of the enzyme, acetyl-CoA carboxylase (ACC), which is believed to be the rate-limiting enzyme of the pathway. Our point of departure in this description is the apparent discrepancy in the literature concerning the zonation of fatty acid synthase (FAS), ATP citrate lyase, and ACC, where opposite activity gradients have been reported by different authors. It is important to try to resolve this discrepancy and, since it is very likely to be linked to differences in methodology, we will focus the discussion on some essential features of the methods used in those studies. Also in this article we briefly review the evidence for a zonation of fatty acid degradation.

\section{Zonation of Fatty Acid Synthesis}

\section{Review of the Apparently Contradictory}

Results

Applying microanalytical techniques on microbiopsies from the PP and PV zones of the liver microcirculation, Katz et al. [3] observed an approximately $60 \%$ higher ACC activity and a 100\% higher activity of ATP citrate lyase [4] in the PV zone of the rat liver (table 1). The zonation in the fasted state was somewhat lower than in the fed and refed state. Previous studies with histochemical and microchemical techniques have shown a similar zonation of the ancillary NADPH-gencrating enzymes although with some controversy, probably due to contamination from nonparenchymal cells [5]. By the same method, zonation of FAS was found to be similar to that of $A C C$ in the female, but not in the male rat [6]. Applying 
the digitonin-collagenase cell isolation technique $[7,8]$ Guzmán and Castro $[9,10]$ observed a $50 \%$ higher rate of fatty acid and very low density lipoprotein synthesis in the PV cells in the liver of fed male rats. In the same system these authors also found a similar zonation of the ACC activity (table 1).

Against this stand the results of Evans et al. [11, 12] and Bianchi et al. [13] who applied the dual-digitonin-pulse perfusion technique [14] and observed a 3-fold gradient of the ACC activity in favor of the PP zone (table 1). Since the ACC protein mass was also measured in those studies, the activity data could be expressed in tcrms of true specific activity. and it was concluded that the specific activity gradient could account for the entire gradient observed [12]. Furthermore, Quistorff et al. [15] did not observe significant zonation of fatty acid synthesis in isolated PP and PV cells in fasted, female rats (table 1). Kera et al. [16] found a $30 \%$ higher activity of glucose-6-phosphate dehydrogenase in isolated PP compared with $P V$ cells, a preparation which ensures no contribution from nonparenchymal cells. Finally, it should be mentioned in this context that Singer et al. [17], applying immunohistochemical techniques, found a strong, or perhaps exclusive, PP zonation of HMGCoA-reductase, the rate-limiting enzyme of sterol biosynthesis. This is, however, complicated by the fact that cholestcrol-7 $\alpha$-hydroxylase, needed for bile acid synthesis, shows the opposite zonation [18].

Thus taken at face value, these sets of observations appear incompatible and one set of data is at variance with the model of metabolic zonation $[1,19]$. It is likely, however, that some important methodological differences play a decisive role and may at least in part explain the differences in the results. We will examine three key methodological parameters: (1) the reference used for expression of data on enzyme activity or on the rate of lipid synthesis: (2) definition of the microcirculatory zones, from which the different methods sample the activities measured, and (3) possible differences in assay conditions, which could systematically affect the outomce of zonation measurements.

\section{Expression of Results:}

\section{Choice of Reference Subsiance}

Most results oblained by the microanaly. sis technique using microdissected samples are expressed per milligram of dry weight, as is the case in the studies by Katz et al. [3, 4, 6], while the studies on isolated hepatocytes are usually expressed per milligram of total protein $[9.10,16]$ or in some studies per milligram of DNA [7, 16]. Contrary to this, the results of Evans et al. [11,12] on the zonation of ACC, applying digitonin-pulse perfusion [14], are expressed per milligram of cytosolic protein or as the true specific activity, since the assay was performed also with the isolated ACC protein. Expressing the data per milligram dry weight or per milligram total protein will, of course, bias the results to the extent that there is a systematic difference in any of these parameters between the zones from which the cells or biopsies are isolated, whilc the true specific activity should be devoid of such bias.

This question of reference substance has been addressed previously in the context of the quantitation of zonation. Hence, Quistorff [20] attempted to evaluate the zonation of the cytosolic protein concentration by the dual-digitonin-pulse perfusion technique. In these experiments it was assumed that the intracellular potassium concentration, which 
Table 2. Total protein content per milligram of DNA in whole liver and in isolated hepatocytes from rat liver

\begin{tabular}{|c|c|c|c|c|}
\hline $\begin{array}{l}\text { Nutritional } \\
\text { state }\end{array}$ & Biopsy & $\begin{array}{l}\text { Control } \\
\text { cells }\end{array}$ & PP cells & PV cells \\
\hline Fed & $\begin{array}{l}145 \pm 34 \\
(n=7)\end{array}$ & $\begin{array}{l}122 \pm 13 \\
(\mathrm{n}=7)\end{array}$ & $\begin{array}{l}121 \pm 15 \\
(n=3)\end{array}$ & - \\
\hline Fasted & $\begin{array}{l}114 \pm 45 \\
(n=9)\end{array}$ & $\begin{array}{l}90 \pm 18 \\
(n=9)\end{array}$ & $\begin{array}{r}89 \pm 13 \\
(n=14)\end{array}$ & $\begin{array}{l}82 \pm 13 \\
(n=6)\end{array}$ \\
\hline
\end{tabular}

Means \pm SD are given with the number of experiments in parentheses. There is no significant difference between control cells, PP and PV cells within individual nutritional groups ( $\mathrm{p}>0.05)$. $\mathrm{PP}$ and $\mathrm{PV}$ cells were isolated according to Quistorff [7].

is very high, about $160 \mathrm{mmol} / \mathrm{l}[21]$, is not significantly different in PP and PV cells. Measuring the protein $/ \mathrm{K}^{+}$ratio in the eluates from the PP and PV zone, no significant difference was found. It was furthermore observed that the elution kinetics of protein and potassium were the same, and it was concluded that the cytosolic protein concentration was equal in the two zones. This conclusion can, of course, be criticized since the inherent assumption of proportional elution of potassium and cytosolic protein is only suggested but not proven by the observation of similar elution kinetics.

Another approach to estimating the protein concentration of the two zones, which may be used with the cell isolation technique as well as with the microdissection technique, is to generate the ratios, milligrams of protein per milligram of DNA and milligrams of protein per milligram dry weight. Quistorff [7] observed that the protein/DNA ratio in biopsies from whole liver and in PP or PV cells isolated by the digitonin-collage- nase technique all amount to approximately $100 \mathrm{mg}$ protein/mg DNA in the fed state and somewhat lower in the fasted state (table 2). Applying microdissection and microanalysis, Morrison et al. [22] found values of 63-65 $\mu \mathrm{g}$ protein $/ 100 \mu \mathrm{g}$ dry weight, identical in the PP and PV zone of the rat, while in human liver the PV value was some $15 \%$ lower [23]. To our knowledge there are no data available on the protein/DNA ratio as measured by the microdissection technique. However, even if these ratios were identical for the PP and PV zones, there may still be a problem since results which are expressed per milligram of total protein may be biased by the fact that the amount of mitochondria and hereby probably the concentration of mitochondrial protein is significantly higher in the PP zone [24]. This may be relevant particularly for ACC, being a cytosolic enzyme, and such bias would contribute to a seemingly higher activity in the PV zone.

With the dual-digitonin-pulse perfusion technique, it appears that only cytosolic protein is being eluted. As judged by the mitochondrial marker enzyme glutamate dehydrogenase, less than $2 \%$ of the mitochondrial compartment is being eluted [25]. Therefore the results obtained with this technique when expressed per milligram of eluted protein may in fact report more accurately on the actual cytosolic activity than results based on total protein measurements.

All in ail, there is a need for a reference substance of known zonal distribution. The available data suggest that total protein as expressed per milligram of DNA is not zonated (table 2), but a study which systematically compares dry weight, total protein and DNA at a high spatial resolution along the sinusoids, as provided in the excellent stud- 
ies by Teutsch [26, 27], would be highly desirable; although it would not, of course, relieve the problem of zonal variations in organel contribution to the total protein concentration and it would not remove the potential bias contributed by nonparenchymal tissue either. Concerning the dual-digitoninpulse perfusion technique, a final solution to the reference problem depends upon defining the 'true' gradient of a cytosolic marker substance and producing more direct proof for actual proportional elution of the marker substance such as $\mathrm{K}^{+}$and the enzymes or metabolites in question. One practical and pragmatic approach when applying this method is to express enzyme activities against a reference enzyme of known activity gradient, e.g. lactate dehydrogenase, or to apply the more complicated procedure of relating the data to potassium concentration [20].

\section{Selectivity of Zonal Sampling}

In most of the literature on metabolic zonation only two zones are defined, a PP and a PV zone [1, 2]. For many enzyme activities this is very probably an oversimplification partly reflecting the inability of most of the techniques to differentiate more than two zones in a practical experiment. Thus, it is well known from several studies applying histological staining, as well as immunohistochemical techniques, that many enzyme activity gradients are nonlinear and that the gradients of different enzymes do in fact define PP and PV zones quite differently (fig. 1). Hence, according to the distribution of glutamine synthase, the PP zone is defined as $85-90 \%$ of the parenchyma while only some $10 \%$ around the terminal hepatic vein containing this enzyme is defined as the PV zone [28]. Cytochrome-P450IIE1 [29] and a number of the enzymes of the urea pathway seem to define the same PP and PV zones [2], while HMG-CoA-reductase [17] defines some $20 \%$ of the initial part of the microcirculation as the PP zone and the remaining $80 \%$ as the $\mathrm{PV}$ zone. Alanine aminotransferase takes an intermediate position by showing an apparently linear gradient, except for a significantly higher activity in the initial PP subzone [30]. Figure 1 schematically shows the distribution gradients of a number of key enzymes.

This aspect of zone definition may be important in relation to the observed difference between the dual-digitonin-pulse perfusion technique on the one hand and the microdissection/microanalysis and cell isolation technique on the other. The dual-digitonin-pulse perfusion provides an extremely high zonal selectivity, usually with elution from only some $10-20 \%$ of the microcirculation from each end of the sinusoids, depending upon the direction of perfusion and the amount of digitonin applied in each pulse $[30,31]$. The digitonin-collagenase cell isolation technique, on the other hand, has a much lower zonal selectivity: the permeabilization of the parenchymal cells along the sinusoids during digitonin perfusion shows a very uniformly distributed front for the initial perfusion. With more extended digitonin perfusion, however, the synchronization of permeabilization in different sinusoids appears to be lost, more so the longer the digitonin perfusion lasts $[14,31]$. Therefore, since the aim of the digitonin perfusion when used for cell preparation is to permeabilize $50 \%$ or more of the parenchymal cells, only moderate selectivity is obtained, which is very clearly shown by the magnitude of the $\mathrm{PP} / \mathrm{PV}$ gradient of alanine aminotransferase observed by the two methods (table 3 ). 


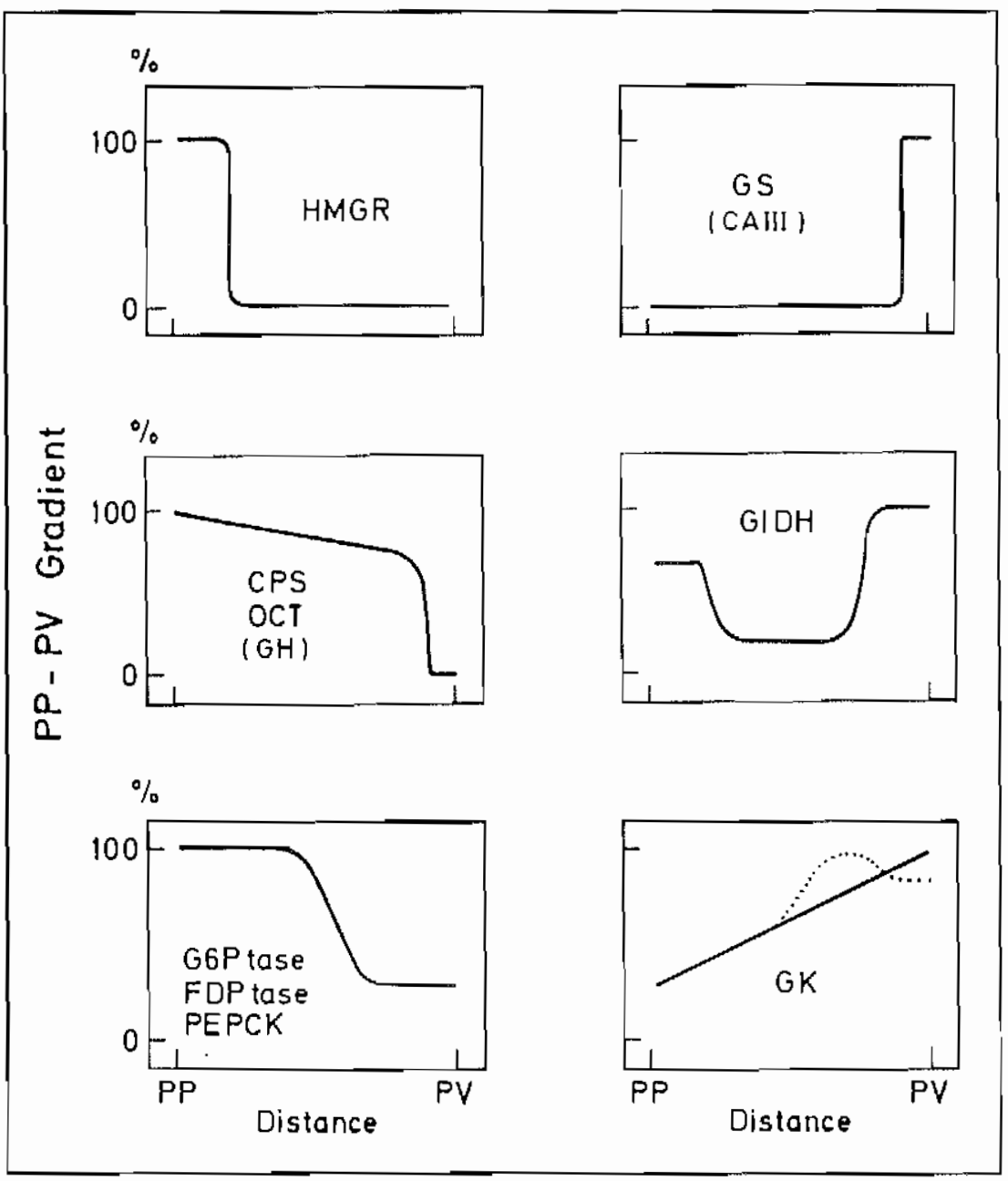

Fig. 1. Enzyme activity gradients across the liver lobule. Since significant factors, such as nutritional state, sex and age, influence the enzyme activity gradients, the gradients are only qualitative indications. HMGR = Hydroxymethylglutaryl-CoA reductase; $\mathrm{GS}=$ glutamine synthetase; $C A=$ carbonic anhydrase; $C P S=$ carbamoylphosphate synthetase II; OCT $=$ ornithine carbamoyltransferase: $\mathrm{GH}=$ glutaminase; G1DH = glutamate dehydrogenase; G6Ptase = glucose6-phosphatase: FDPtase = fructose-1.6-bisphosphatase: PEPCK = phosphoenolpyruvate carboxykinase; $G K=$ glucokinase. Reproduced from Quistorff [2] with permission.
Thus, it is clear that the dual-digitoninpulse perfusion technique will report enzyme activity in a much more well-defined zone than the cells isolated by the digitonincollagenase method and that it will report cytosolic activities only. Under standard conditions the microdissection/microanalysis technique is also aimed at sampling some $30-50 \%$ of the microcirculatory zone $[3,4$, 6]. Potentially, however, the microdissection technique can sample very accurately, as indeed demonstrated by several studies aimed at describing the shape of the enzyme activity gradients along the sinusoid [26, 27]. However, such studies have not yct been per- formed for $\mathrm{ACC}$, but would be most interesting in order to evaluate the possible presence of a nonlinear activity gradient.

Using the digitonin-pulse perfusion technique, it is consistently observed that a 15$20 \%$ larger amount of protein is eluted from the PP than from the PV zone applying the same amount of digitonin $[11,12,14,20,25$, $30,31]$. Whether this reflects a higher cholesterol content of the plasma membrane of cells in the PV zone, causing fewer cells of that zone to be permeabilized, is not known at present.

In summary, it seems clear that the data obtained by the digitonin-pulse perfusion re- 
fer to an initial PP and PV subzone, considerably smaller than the zones examined by the cell isolation technique and microdissection studies reviewed here. Hence, it is possible that subzonal ACC activity gradients and/or ACC phosphatase and ACC kinase could explain the apparent discrepancy of results.

\section{Differences in Methodology of ACC Measurement}

A critical difference between the conflicting studies is the method used to estimate ACC activity (table 4). ACC in the liver is subject to complex regulation and, as such, accurate measurement of ACC activity and enzyme polypeptide content may be subject to considerable variability depending on the analyses performed. Hepatic ACC consists of two distinct isoforms of 265,000 and 280,000 molecular weight on denaturing SDS gels [32, 33]. The former constitutes about $90 \%$ of the total ACC content, as judged by Coomassie blue staining; however, the two isoforms cannot be separated under nondenaturing conditions. Thus, the individual specific activities of the two isoforms and the contribution of each to total activity is unknown. Furthermore, the two isoforms exist in a heteroisozymic complex and the mass of this complex varies in parallel with total enzymatic activity during nutritional manipulation [33]. Changes in total activity (measured at a saturating citrate concentration) could therefore be quite complex, reflecting not only the individual specific activities of the two isoforms, but also the activity of the heteroisozymic complex. The content of the two isoforms in the PP and $P V$ zones of the liver appears to vary in parallel under varying conditions of nutrition, as judged by the dual-digitonin perfusion
Table 3. Comparison of PP/PV activity ratio of alanine aminotransferase as measured by different preparation methods

\begin{tabular}{|c|c|c|c|c|}
\hline Method & $\mathrm{PP}$ & PV & $\mathrm{PP} / \mathrm{PV}$ & $\begin{array}{l}\text { Refer- } \\
\text { ence }\end{array}$ \\
\hline \multirow{4}{*}{$\begin{array}{l}\text { Isolated PP } \\
\text { and PV cells }\end{array}$} & 172 & 117 & 1.5 & 45 \\
\hline & 112 & 69 & 1.5 & 9 \\
\hline & 288 & 97 & 2.8 & $7^{a}$ \\
\hline & 245 & 116 & 2.1 & 8 \\
\hline $\begin{array}{l}\text { Dual-digitonin- } \\
\text { pulse perfusion }\end{array}$ & 907 & 100 & 9.0 & $15^{\mathrm{b}}$ \\
\hline Microdissection & 278 & 120 & 2.3 & $22^{\mathrm{c}}$ \\
\hline
\end{tabular}

a Data are given as $\mathrm{mU} / \mathrm{mg}$ total protein.

b Data are the average of $0-30 \mathrm{sec}$ eluates.

c Data are converted to $\mathrm{mU} / \mathrm{mg}$ protein applying the values for $\mu \mathrm{g}$ dry weight given by Morrison et al. [22].

technique [12]; their content in microdissected liver samples in isolated cells has not been investigated.

Measured ACC activity can be highly variable as a result of posttranslation modification that can rapidly occur during cell breakage or likely even in permeabilized cells. ACC is regulated by multi-site enzyme phosphorylation and dephosphorylation catalyzed by several discrete protein kinases and protein phosphatases $[34,35]$. For the purposes of the present discussion, it is extremely important to point out the propensity of the enzyme to postcollection changes in the phosphorylation state, if samples are not rapidly processed in the cold (or with freezing) or if they are collected in a buffer that does not include inhibitors of protein phosphatases [34, 36-39]. This postcollection modification may result either in enzyme inactivation by endogenous protein ki- 
Table 4. Comparison of ACC activity tests

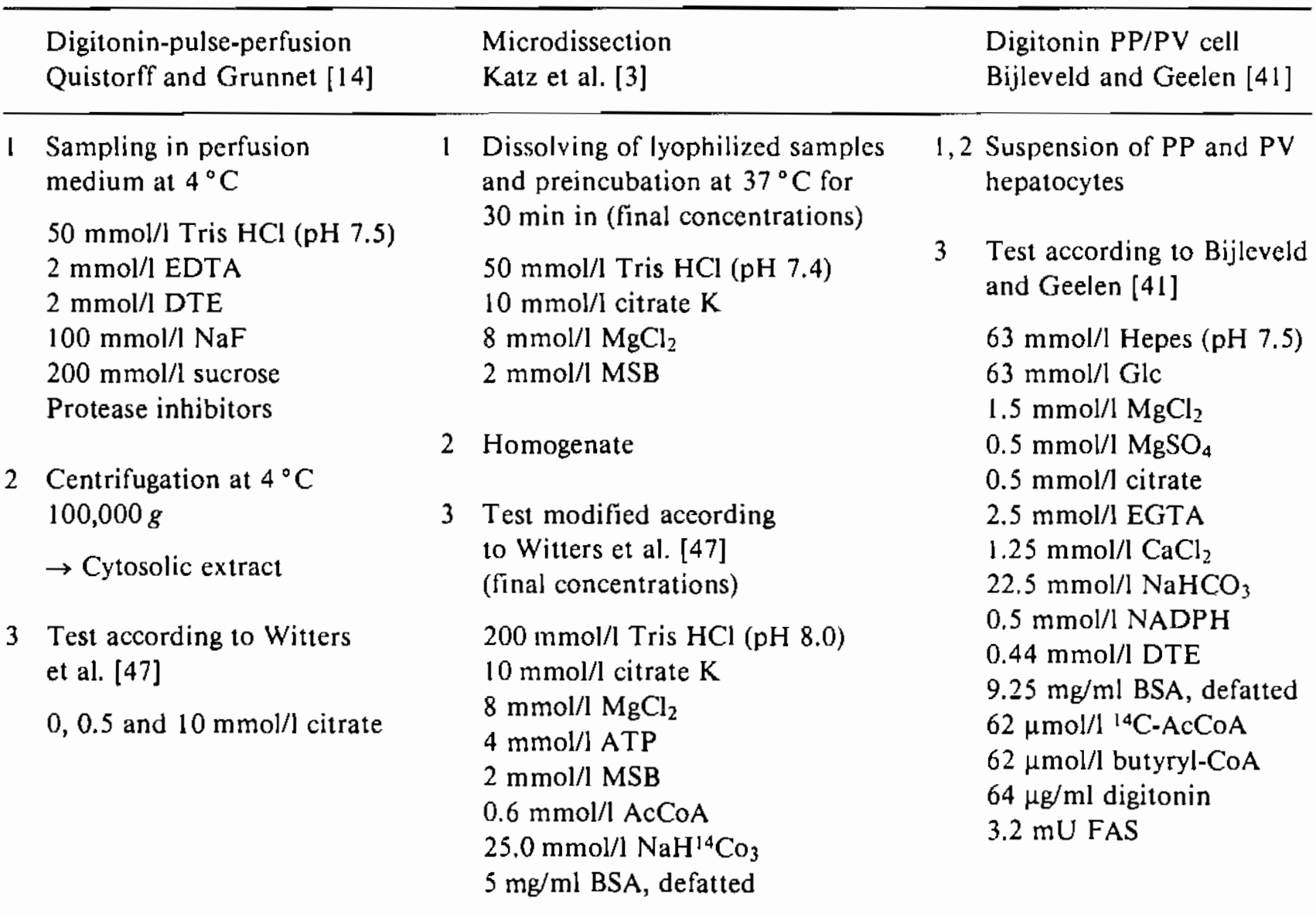

Test reaction applied:

${ }^{14} \mathrm{HCO}_{3}+\mathrm{AcCoA} \rightarrow{ }^{14} \mathrm{C}-\mathrm{MalCoA}$

${ }^{14} \mathrm{C}-\mathrm{AcCl} \mathrm{CoA} \rightarrow{ }^{14} \mathrm{C}$ fatty acids

nases, lowering enzyme-specific activity, or enzyme activation due to phosphatase action or combinations of each. It is also well recognized that ACC is very sensitive to proteolysis and that even minor degrees of exoproteolysis of the $\mathrm{N}$-terminal phosphorylation site(s) results in enzyme activation [39]. Thus, failure to include a 'cocktail' of protease inhibitors in the collection buffer may influence the measured activity.

Both changes in enzyme phosphate content and/or postcollection proteolysis alter enzyme activity at $V_{\max }$ measured in the presence of saturating citrate $(5-30 \mathrm{mmol} / \mathrm{l})$ and at varying subsaturating concentrations of this allosteric activator. However, $\mathrm{V}_{\max }$ activity is a very poor reporter of the activity state of ACC; changes in enzyme velocity due to changes in enzyme phosphorylation, for example, are reflected with much greater fidelity in assays conducted either in the absence of citrate or at subsaturating concentrations $[11,12,33-38,40]$, reflecting the intracellular conditions (cytosolic citrate concentrations of about $300 \mu \mathrm{mol} / \mathrm{l}$ ) much closer than those employed in $\mathrm{V}_{\max }$ assays. 
This kinetic assessment has only been performed in the studies of Evans et al. [11, 12] with sample collection by dual-digitoninpulse perfusion in the presence of phosphatase/protease inhibitors and enzyme assay at variable citrate concentrations. Their measured zonation to the PP zone is much more apparent in assays conducted at subsaturating citrate concentrations or in the absence of citrate, suggesting that the PP enzyme is dephosphorylated relative to the PV enzyme [12].

The reports of ACC activity in microdissected cell lysates by Katz et al. [3] or with cell permeabilization have also employed a period of preincubation of the enzyme in the presence of saturating citrate (and excess divalent cation, $\mathrm{Mg}^{2+}$, which serves to heighten the activity of endogenous protein phosphatases) prior to substrate addition in the assay; these preincubation mixtures did not include either phosphatase or protease inhibitors, likely resulting in considerable enzyme modification occurring during the assay. Therefore, the conditions employed in these latter studies very likely yield enzyme activity results that reflect, in part, postcollection enzyme status and which are not sensitive to discern the actual in vivo differences in ACC between the PP and PV zones.

The measurement of actual enzyme content directly by immunoblotting and ELISA $[11,12]$ permit expression of true specific activity (as units per milligram of ACC polypeptide). These calculated values clearly indicate a PP:PV gradient that is not contributed to substantially by differences in ACC content of either isoform. Such a gradient would be missed in the assay conditions applied in the study by Katz et al. [3]. Analysis of ACC isolated to homogeneity in the pres- ence of phosphatase and protease inhibitors by monomeric avidin-Sepharose chromatography indicate that this gradient is due both to differences in ACC phosphorylation between the hepatic zones and differences in apparent allosteric regulation [12]. These differential changes in ACC phosphorylation between the two zones could well reflect differences in the distribution of important ACC phosphatases (as measured by Evans et al. [12]) and in ACC kinase activity [Witters and Quistorff, unpublished].

A completely different assay was applied to measure ACC in suspensions of hepatocytes enriched from the PP and from the PV zone, respectively $[9,10]$. After permeabilization of the isolated cells by digitonin the incorporation of ${ }^{14} \mathrm{C}$-acetyl-CoA into fatty acids were tested in the presence of exogenous FAS [41]. Since the ACC might be released from the permeabilized hepatocytes into the suspension medium, it remains uncertain whether this test reflects precisely the in vivo situation of zonal heterogeneity. In fact, as suggested in the previous sections, the same amount of digitonin may permeabilize a larger fraction of PP than PV cells, which in this context could lead to an apparent PV zonation of ACC due to a more pronounced loss of enzyme from PP than PV cells. However, this hypothetical source of error would not, of course, explain the higher rate of fatty acid synthesis measured in intact PV cells $[9,10]$.

\section{Conclusion}

Each of the threc methods for studying metabolic zonation discussed here has its shortcomings and advantages. While microdissection can be carried to very high spatial resolution one basic drawback is the inability to differentiate parenchymal cells 
from stroma and nonparenchymal cells. This problem seems to be completely solved for the cell isolation technique, which, however, suffers a relatively low zonal selectivity at the present level of methodological sophistication. Future developments of the cell sorting technique based on various forms of functional in vivo labelling holds significant promise [42], but appear to be limited in the cell yield/stability of the preparation during isolation [43]. In this context, the technique of Misra et al. [44], isolating cell plugs from the PP and PV zones on the liver surface, is very interesting, although it seems to be limited both in terms of yield and by the same problems which complicate the experiments with tissue slices. The digitonin-pulse perfusion adds an important new feature by allowing very rapid sampling of $P P$ and $P V$ cytosol with high zonal selectivity. This technique, however, does not differentiate between parenchymal and nonparenchymal cells and is limited at present by some uncertainty about whether all cytosolic enzymes are sampled proportionally and/or by the lack of a proper reference substance. However, both of these shortcomings would appear to be eliminated when the actual mass of proteins in question is measured in the eluates allowing calculation of true specific activity. For experiments which require a fast and reliable sampling of cytosolic proteins or metabolites, this technique appears to be ideal.

In summary at least three factors can be identified which might explain the present discrepancy of results on ACC zonation. The first is the bias caused by the use of different references in the expression of the results. In this context, especially the zonal difference of mitochondria may play a role. The second is related to the fact that the digitonin-pulse perfusion reports the activity in a much narrower zone than the other methods applied so far in the study of zonation of lipogenesis. Hence subzonal activity differences may well be a contributing factor. If, for example, the glutamine synthase subzone were significantly lower in ACC activity than the remaining PV zone, this would affect the digitonin-pulse perfusion results much more strongly than the results obtained by isolated cells or by microdissection. The third factor is related to the unequal distribution of the enzymes which modify ACC convalently as indeed seems to be the case with a higher activity of the ACC phosphatase in the PP subzone. The assay and extraction conditions used in the microdissection studies eliminates such differences by applying preincubation with high citrate and $\mathrm{Mg}^{2+}$. A possible fourth factor concerns the assay conditions used in the isolated hepatocytes $[9,10,41]$, where a leakage from PP and PV cells of ACC may be different and thereby bias the results.

\section{Zonation of Fatty Acid and Degradation}

In liver the fatty acids are utilized for oxidative energy supply, for ketogensis and for synthesis of triglycerides. Since the oxidative capacity is higher in PP hepatocytes, it was postulated that the degradation of fatty acids via $\beta$-oxidation should also be localized in this zone [1]. In fact, several enzymes involved in the intracellular transport of fatty acids as well as in $\beta$-oxidation were found to be higher in PP than in PV hepatocytes [1]. As demonstrated by immunohistochemical studies and by selective zonal destruction, the fatty acid-binding protein is about 1.6fold higher in PP compared to PV tissue 
[45]. Carnitine palmitoyltransferase, responsible for the mitochondrial uptake of fatty acids, was found to be significantly higher in PP than in PV hepatocytes $[10,46]$. Moreover, a slight PP predominance in the activity of the enzyme 3-hydroxyacyl-CoA dehydrogenase of the $\beta$-oxidation pathway was reported in two studies $[3,22]$, but this was not corroborated in a later study [46].

The $\mathrm{CO}_{2}$ production by oxidative degradation of palmitate and other fatty acids was found to be 1.35-fold higher in hepatocyte preparations enriched in $\mathrm{PP}$ compared to $\mathrm{PV}$ cells [10]. On the other hand, ketogenesis from fatty acids was slightly but not significantly higher in PP hepatocytes cultured in the absence of glucagon [46]. However, after preincubation in the presence of glucagon, PP hepatocytes exhibited a significantly higher rate of fatty acid-dependent ketogenesis [46]. The 3-hydroxybutyrate/acetoacetate ratio was slightly higher in PV cells, suggesting a more reduced state in that zone [46]. Thus, in general the zonal differences in fatty acid oxidation appear to be less pronounced than those in lipogenesis. All in all lipid metabolism seems to be less zonated than carbohydrate and amino acid metabolism.

\section{Zonation of Gene Expression of the Enzymes of Fatty Acid Metabolism}

There are only preliminary data on the zonal distribution of ATP citrate lyase mRNA. As demonstrated by in situ hybridization, the ATP citrate lyase mRNA did not exhibit a significant prevalence in the PP or PV zone [Evers et al., unpublished results]. No information seems to be available on the zonal distribution of mRNA of other enzymes involved in lipid metabolism.

\section{References}

I Jungermann K, Katz N: Functional specialization of different hepatocyte populations. Physiol Rev 1989;69:708-764.

2 Quistorff B: Metabolic heterogeneity of liver parenchymal cells. Essays Biochem 1990;25:83136.

3 Katz NR, Fischer W, Giffhorn S: Distribution of enzymes of fatty acid and ketone body metabolism in periportal and perivenous rat-liver tissue. Eur J Biochem 1983:135:103-107.

4 Katz NR, Fischer W, Ick M: Heterogeneous distribution of ATP-citratc-lyase in rat-liver parenchyma. Microradiochemical determination in microdissected periportal and perivenous liver tissue. Eur J Biochcm 1983;130:297-301.

5 Teutsch HF: Chemomorphology of liver parenchyma. Qualitative histochemical distribution patterns and quantitative sinusoidal profiles of G6Pase, G6PDH and malic enzyme activity and of glycogen content. Prog Histochem Cytochem 1981:14(3):1-92.

6 Katz N, Thiele J, Giffhorn-Katz S: Zonal distribution of fatty acid synthase in liver parenchyma of male and female rats. Eur J Biochem 1989;180: 185-189.

7 Quistorff B: Gluconeogenesis in periportal and perivenous hepatocytes of rat liver, isolated by a new high yield digitonin-collagenase perfusion technique. Biochem J 1985;229:221-226.

8 Lindros KO, Penttilä KE: Digitonin-collagenase perfusion for efficient separation of periportal or perivenous hepatocytes. Biochem J 1985;228: $757-760$.

9 Guzmán M, Castro J: Zonation of fatty acid metabolism in rat liver. Biochem J 1989;264:107113.

10 Guzmán M, Castro J: Zonal heterogeneity of the effects of chronic ethanol feeding on hepatic fatty acid metabolism. Hepatology 1990;12:10981105.

11 Evans JL, Quistorff B, Witters LA: Zonation of hepatic lipogenic enzymes identified by dual-digitonin-pulse perfusion. Biochem J 1989;259:821829.

12 Evans JL, Quistorff B, Witters LA: Hepatic zonation of acetyl-CoA carboxylase activity. Biochem J 1990:270:665-672.

13 Bianchi A, Quistorff B. Witters LA: Hepatic zon- 
ation of insulin-stimulated tyrosine phosphorylation. FEBS Lett 1990;269:435-439.

14 Quistorff B, Grunnet N: Dual-digitonin-pulse perfusion: Concurrent sampling of periportal and perivenous cytosol of rat liver for determination of metabolites and enzyme activity. Biochem $\mathrm{J}$ 1987;243:87-95.

15 Quistorff B, Dich J, Grunnet N: Pcriportal and perivenous hepatocytes retain their zonal characteristics in primary culture. Biochem Biophys Res Commun 1986;139:1055-1061.

16 Kera Y, Sippel HW, Penttilä KE, Lindros KO: Acinar distribution of glutathione-dependent detoxifying enzymes. Biochem Pharmacol 1987;36: 2003-2006.

17 Singer II, Kawka DW, Kazazis DM, Alberts AW, Chen JS, Hoff JW, Ness GC: Hydroymethylglutaryl-CoA reductase containing hepatocytes are distributed periportally in normal and mevinolin treated rat livers. Proc Natl Acad Sci USA 1984; 81:5556-5560.

18 Ugele B, Kempen HJM, Gebhardt R, Meijer P, Burger H-J, Princen HMG: Heterogeneity of rat liver parenchyma in cholesterol 7a-hydroxylase and bile acid synthesis. Biochem J 1991;276:7377.

19 Katz N, Jungermann K: Autoregulatory shift from furctolysis to lactate gluconeogenesis in rat hepatocyte suspensions. The problem of metabolic zonation of liver parenchyma. Hoppe-Seylers Z Physiol Chem 1976;457:359-375.

20 Quistorff B: Digitonin perfusion in the study of metabolic zonation of the rat liver. Potassium as intracellular concentration reference. Biochem Soc Trans 1987;1 5:361-363.

21 Christensen L $\varnothing$, Folke M: Volume regulatory $\mathrm{K}^{+}$ efflux during concentrative uptake of alanine in isolated rat hepatocytes. Biochem J 1984;22:265268.

22 Morrison GR, Brock FE, Karl 1E, Shank RE: Quantitative analysis of regenerating and degenerating areas within the lobule of the carbon tetraehloride-injured liver. Arch Biochem Biophys 1965;111:448-460.

23 Morrison GR, Karl IE, Schwartz R, Shank RE: The quantitative histochemistry of the normal human liver lobule. J Lab Clin Med 1965;65:248256.

24 Swick RW, Stange JL, Nance SL, Thomson JF: The heterogenous distribution of mitochondrial enzymes in normal rat liver. Biochemistry 1967;6: 737-744.

25 Knudsen CT, Immerdal L, Grunnet N, Quistorff B: Zonation of the cytosolic acetyl-CoA synthase of rat liver. Eur J Biochem 1991, in press.

26 Teutsch HF: Regionality of glucose-6-phosphate hydrolysis in the liver lobule of the rat: Metabolic heterogencity of 'portal' and 'septal' sinusoids. Hepatology 1988;8:311-317.

27 Teutsch HF: Quantitative histochemical assessment of regional differences in hepatic glucose uptake and release. Histochemistry 1985;82:159164.

28 Gebhardt R: Heterogencous intrahepatic distribution of glutamine synthetase. Acta Histochem 1990;40(suppl):23-28.

29 Ingelmann-Sundberg M, Johansson I, Penttilä $\mathrm{KE}$, Glaumann $\mathrm{H}$, Lindros $\mathrm{KO}$ : Centrilobular expression of ethanol-inducible cytochrome P.450 (IIE1) in rat liver. Biochem Biophys Res Commun 1988;157:55-60.

30 Quistorff B, Rømert P, Evans JL, Witters LA: Digitonin-pulse perfusion in the study of zonation of cytosolic hepatic proteins; in Grunnet N, Quistorff B (eds): Regulation of Hepatic Function. Metabolic and Structural Interactions. Alfred Benzon Symposium, No. 30. Copenhagen, Munksgaard, 1991, pp 47-71.

31 Quistorff B, Rømert P: High zone-selectivity of cell permeabilization following digitonin-pulse perfusion of rat liver: A re-interpretation of the microcirculatory zones. Histochemistry 1989;92: 487-498.

32 Bianchi A, Evans JL, Watts TD, Witters LA: Identification of an isozymic form of acetyl-CoA carboxylase. J Biol Chem 1990;265:1 502-1508.

33 Iverson AJ, Nordlun A-C, Witters LA: Immunological analysis of acetyl-CoA carboxylase mass, tissue distribution and subunit composition. Biochem J 1990;269:365-371.

34 Witters LA: Protein kinases and phosphatases active on acetyl-CoA carboxylase. Adv Protein Phosphatases 1986;3:201-224.

35 Hardie DG: Regulation of fatty acid synthesis via phosphorylation of acetyl-CoA carboxylase. Prog Lipid Res 1989;28:117-146.

36 Moir MB, Zammit VA: Changes in the properties of cytosolic acetyl-CoA carboxylase studied in cold-clamped liver samples from fed, starved and starved/refed rats. Biochem J 1990;272:511-517. 
37 Jamil H, Madsen NB: Phosphorylation state and acetyl-CoA carboxylase. II. Variation with nutritional condition. J Biol Chem 1987;262:638642.

38 Thampy KG, Wakil SJ: Regulation of acetyl-CoA carboxylase. 11. Effect of fasting and refeeding on the activity, phosphate content, and aggregation of the enzyme. J Biol Chem 1988;263:64546458.

39 Guy PS, Hardie DG: Rapid removal of one of the phosphorylation sites on acetyl-CoA carboxylase by limited proteolysis. Biochem Soc Trans 1980; 8:387-388.

40 Witters LA, Watts TD, Daniels DL, Evans JL: Insulin stimulates the dephosphorylation and activation of acetyl-CoA carboxylase. Proc Natl Acad Sci USA 1988:85:5473-5477.

4I Bijleveld C, Geelen MJH: Measurement of acetylCoA carboxylase activity in isolated hepatocytes. Biochim Biophys Acta 1987;918:274-283.

42 Gumucio JA, Miller DL, Krauss MD, Zanolli CC: Transport of fluorescent compounds into hepatocytes and the resultant zonal labelling of the hepatic acinus in the rat. Gastroenterology 1981;80: 639-646.

43 Braakman I: Hepatocyte Heterogeneity in Organs Cation Transport; thesis University of Groningen, The Netherlands, 1987, pp 99-120.
44 Misra UK, Yamanaka H, Kizaki FC, Kauffman FC, Thurman RG: A new method for the isolation of fresh hepatocytes from periportal and pericental regions of the liver lobule. Biochem Biophys Res Commun 1988:155:455-462.

45 Bass NR, Barker ME, Manning JA, Jones AL, Ockner RK: Acinar heterogeneity of fatty acid binding protein expression in the liver of male, female and clofibrate-treated animals. Hepatology 1989:9:12-21.

46 Tosh D, George K, Alberti MM, Agius L: Glucagon regulation of gluconeogenesis and ketogenesis in periportal and perivenous rat hepatocytes. Biochem J 1988;256:197-204.

47 Witters LA, Moriarity D, Martin DB: Regulation of hepatic acetyl-CoA carboxylase by insulin and glucagon. J Biol Chem 1979:254:6644-6649.

Bjorn Quistorff

NMR Center

Panum Institute

Blegdamsvej 3

DK-2200 Copenhagen (Denmark) 


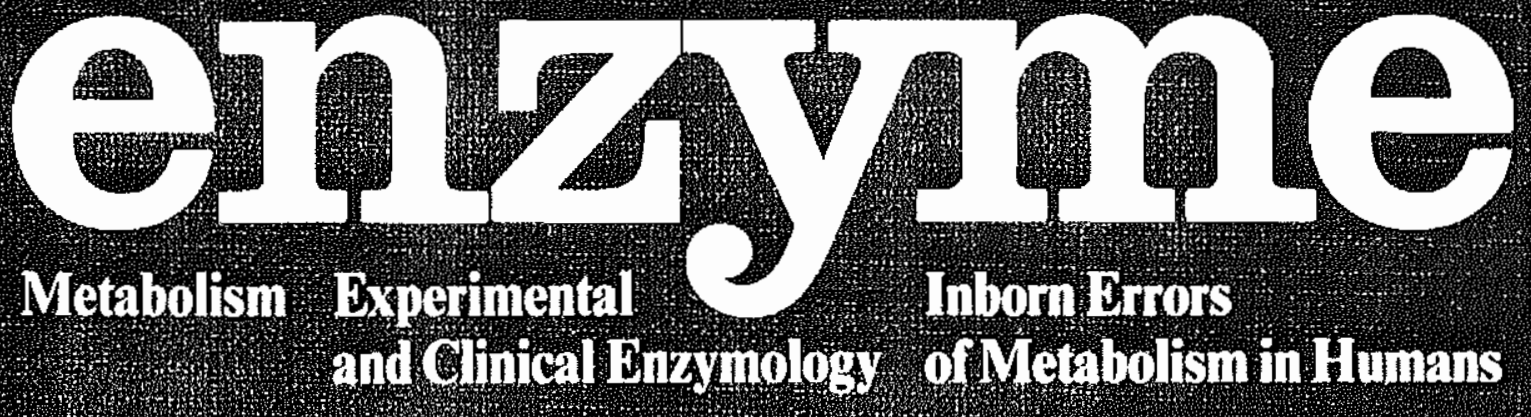

\section{6/1-3/92}

Released December 1992

$$
\begin{aligned}
& \text { 1) } \\
& \text { is } \\
& \text { (3) } \\
& \text { (4) }
\end{aligned}
$$

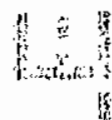

$$
\begin{aligned}
& \text { 1.tms }
\end{aligned}
$$

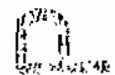

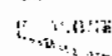

$$
\begin{aligned}
& \text { con } \\
& \text { (1) }
\end{aligned}
$$

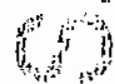
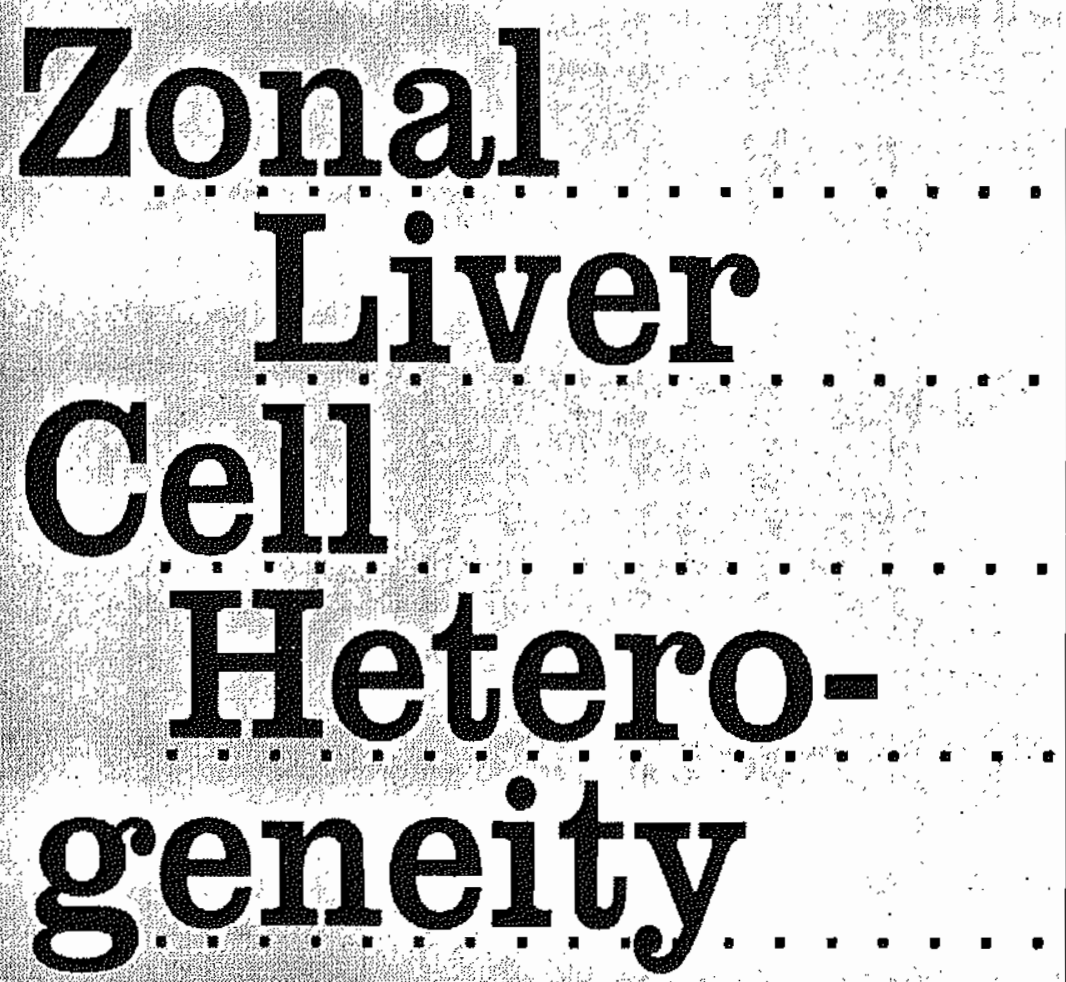

\section{S. Karger}

Medical and Scientific Publishers

Basel · Freiburg

Paris - London

New York - New Delhi Bangkok $\cdot$ Singapore

Editor:

K. Jungermann, Göttingen 